\title{
Gefitinib and bicalutamide show synergistic effects in primary cultures of prostate cancer derived from androgen-dependent naive patients
}

\author{
CLAUDIO FESTUCCIA $^{1}$, GIOVANNI LUCA GRAVINA ${ }^{2}$, PAOLA MUZI ${ }^{1}$, LEDA BIORDI ${ }^{1}$, \\ PIERO RONCHI $^{2}$, ORESTE MARTELLA ${ }^{2}$, CARLO VICENTINI $^{2}$ and MAURO BOLOGNA ${ }^{1,4}$ \\ Departments of ${ }^{1}$ Experimental Medicine, ${ }^{2}$ Surgery and ${ }^{3}$ Basic and Applied Biology, \\ University of L'Aquila, 67100 L'Aquila, Italy
}

Received June 5, 2007; Accepted July 25, 2007

\begin{abstract}
We previously demonstrated that the inhibition of the epidermal growth factor receptor (EGFR) signalling affects the endocrine therapy responses of prostate cancer $(\mathrm{PCa})$ cells and that bicalutamide (BCLT) is able to reinforce PI3K activity through mechanisms involving PTEN decrement and EGFR and Her2 activities. The aim of this study was to evaluate if the hormonal therapy with BCLT can affect the EGFR-targeted therapy using primary cultures obtained from 22 human PCa tissues harvested after radical prostatectomy (RP) in patients who received $(n=10)$ BCLT and those that did not $(n=12)$ as neoadjuvant hormone therapy (NHT). We demonstrated that cultures derived from PCa tissues harvested after NHT presented significantly higher EGFR and Her2 levels compared to cultures derived from control patients. However, cultures derived from patients with NHT were less sensitive to gefitinib when compared to cultures derived from control patients. Conversely, BCLT effectiveness did not seem to be different in the two groups and was partially additive with gefitinib in the NHT group and additive/synergistic in the control group. Cultures (8/22) were negative for the expression of the PTEN gene and we observed no differences in the two groups. Thus the different $\mathrm{IC}_{50}$ values observed for gefitinib and the partial additivity in the combination treatment with gefitinib and BCLT is influenced by EGFR/Her2 ratio because it was shown that EGFR
\end{abstract}

Correspondence to: Dr Claudio Festuccia, Department of Experimental Medicine, Via Vetoio, Coppito-2, 67100 L'Aquila, Italy E-mail: festucci@univaq.it

Abbreviations: PCa, prostate cancer; AAT, androgen ablation therapy; HRPC, hormone refractory prostate cancer; NHT, neoadjuvant hormone therapy; EGFR, epidermal growth factor receptor; PI3K, phosphoinositide 3 kinase

Key words: epidermal growth factor receptor, Her2, hormone refractory prostate cancer, hormone therapy inhibition was lower when Her2 is overexpressed. Taken together, our results indicate that anti-EGFR targeted therapies and a possible combination therapy involving gefitinib and BCLT should be performed early in naive patients when Her2 is not overexpressed and before the antiandrogenic hormone therapy induces such an undesirable effect.

\section{Introduction}

Prostate cancer (PCa) is a complex disease in which different clinical and biological phases of both the natural and treated history of the process may be characterized. To date, no effective therapeutic treatment prevents $\mathrm{PCa}$ progression to more advanced and invasive disease forms. At present, endocrine therapy represents the only suitable treatment, besides surgery, for patients with early-stage PCa. Unfortunately, the beneficial actions of existing endocrine measures are, in part, counteracted by the capacity of the tumor cells to eventually circumvent the use of steroid hormones, allowing them to continue to grow and progress despite such therapy. After a positive initial response, the tumors recur in an androgen-independent (AI) form that is unresponsive to additional androgen withdrawal. For these reasons, additional targets and therapies are needed in conjunction with androgen ablation. The pathways that underlie tumor progression, invasion and resistance to treatment in each clinical state are being increasingly understood and novel biological agents that target these pathways are in development or are now available for clinical testing. On the other hand, the establishment of new biomarkers is needed to identify high-risk patients as candidates for new (adjuvant) therapies and to find new surrogate endpoints to assess the efficacy of these treatments (1). In the past 10 years, conflicting results on HER-2/neu expression in prostate cancer were reported (2-8). Furthermore, it was proposed that Her 2 and androgen receptors function synergistically in the absence of androgens (9-11). This fact suggests the existence of a cross-talk between the Her2/neu and androgen receptor pathways. However, treatment with the anti-Her $2 /$ neu antibody trastuzumab $(12,13)$, which is efficient in breast cancers with 
amplification-driven Her2/neu overexpression, as well as with pertuzumab, an anti-Her2 antibody which inhibits its heterodimerization $(14,15)$ has failed in advanced prostate cancers despite experimental evidence of a favourable response in prostate cancer xenograft models $(16,17)$. However, the reasons for treatment failure of anti-Her2 therapy are not entirely clear. One explanation may be the lack of Her2/neu gene amplification in prostate cancer and the low prevalence of Her2/neu overexpression (8).

Recent studies suggest that gefitinib induces cell cycle retardation and apoptosis and inhibits the growth of several types of human cancer cells expressing EGFR both in vitro and in vivo (18-30). In preclinical studies, gefitinib, a selective inhibitor of epidermal growth factor receptor-tyrosine kinase, produced growth inhibition in a wide variety of common solid tumor types including human PCa xenografts.

The study of prostate carcinogenesis and tumor progression is made difficult by the lack of appropriate in vitro and in vivo models. The most widely used cancer cell lines, which have been established from human metastatic lesions, do not accurately recapitulate the biological behaviour of primary tumors as compared to primary cultures generated from clinical PCa specimens. A procedure to propagate human prostatic epithelial cells in vitro for a limited number of cell generations has been developed by and optimized for prostate cancer cells from primary tumors. During the past fifteen years, in our laboratory we have processed more than $400 \mathrm{PCa}$ and BPH tissue samples (31-33). To test the hypothesis that the inhibition of the EGFR/HER1 signaling pathway may modify the antitumor effects of endocrine therapy, gefitinib and BCLT were administered to human PCa cells in primary cultures derived from tissue samples harvested by radical prostatectomy in patients who received or not BCLT treatment as neoadjuvant hormone therapy (NHT).

In this study, the effects of a combination treatment with gefitinib with BCLT, were determined on a series of 22 human PCa primary tissue cultures.

\section{Materials and methods}

Reagents and cell lines. All the materials for tissue culture were purchased from Hyclone (Cramlington, NE, USA). Plastic ware was obtained from Nunc (Roskilde, Denmark). EGF was purchased from Sigma Chemical (St. Louis, MO, USA). Charcoal/stripped foetal calf serum (CT/FCS) was obtained from Gibco (Gibco Brl, Gaithersburg, MD). Gefitinib and bicalutamide were obtained from AstraZeneca (Macclesfield, UK). Antibodies were purchased from Santa Cruz Biotechnology, Inc (Santa Cruz, CA, USA) unless otherwise indicated. Akt/protein kinase B (PKB) activity was tested using a non-radioactive assay kit (StressXpress AKT/PKB Elisa kit) which was purchased from Stressgene Bioreagents (Victoria, BC, Canada) on cell lysates after partial purification on a MonoQ exchange column (2 $\mathrm{mg}$ protein in $1 \mathrm{ml}$ column) with $10 \mathrm{mM}$ MOPS, pH 7.2, $25 \mathrm{mM}$ b-glycerophosphate, $5 \mathrm{mM}$ EGTA, $2 \mathrm{mM}$ EDTA, $2 \mathrm{mM}$ sodium orthovanadate and $2 \mathrm{mM}$ dithiothreitol and eluted using a $12 \mathrm{ml}$ linear $\mathrm{NaCl}$ gradient $(0-0.8 \mathrm{M} \mathrm{NaCl})$ with a flow rate of $0.5 \mathrm{ml} /$ min. We collected fractions between 0.25 and $0.5 \mathrm{ml}$ for analysis.
Patient selection, study design and treatment. Patients were recruited in our institution between January 2004 and March 2006. In this trial, the basic eligibility criterion was to have a histologically proven and operable (cT2/T3, N0, M0) PCa. Additional eligibility criteria were the absence of prior hormonal therapy including any form of therapy with 5- $\alpha$ reductase inhibitor and the absence of radiation and chemotherapy for $\mathrm{PCa}$, no prior investigational agents and life expectancy $>10$ years. Patients were excluded if they had any prior malignancy within the last five years or had any other serious medical or psychiatric condition or illness that would not permit the patients to be managed according to the protocol. Our institutional review board approved the protocol and written informed consent was obtained before any medical treatment or BCLT before RP. Treated group subjects were assigned to receive medical therapy with $150 \mathrm{mg} / \mathrm{d}$.i.e. BCLT before RP. Untreated group subjects received RP alone and were used as a control. During the treatment period, patients were evaluated for adverse effects (AEs) at baseline and every four weeks, until four weeks after treatment withdrawal. Baseline visit was performed at the time of randomization. We analysed a 22 patient cohort with clinically localized tumors that were surgically treated with RP. Among these, 12 patients received RP as initial treatment (group 1), whereas the other 10 patients received NHT for 4 months based on casodex (150 mg/d.i.e.) treatment (group 2). 'BCLT (Casodex)' and 'Gefitinib (Iressa)' are trademarks of the AstraZeneca group of companies.

Primary cultures from prostate specimens. Tissue samples were collected by needle biopsy or radical prostatectomy from patients attending the urology clinic at the University of L'Aquila Medical School, following standardised clinical procedures. Tissue samples were cultured in DMEM as previously described (31-33). Cultured cells were analysed for the presence of AR, EGFR, prostate-specific antigen (PSA) and telomerase activity, TRAP (34).

Immunoperoxidase staining. Cells were cultured in Lab-Tek Chamber slides (Nalgene Nunc International) and treated as described in the 'Growth assays' section. After 24-48 h of cell culture, cells were washed in PBS and fixed either in $4 \%$ PBS-paraformaldehyde for $5 \mathrm{~min}$ for immunostaining of membrane-associated antigens (EGFR/Her2) or in cold 1:1 acetone: methanol mixture in ice for $2 \mathrm{~min}$ for immunostaining of cellular or nuclear antigens (PSA and AR). Primary and secondary antibodies were used according to the manufacturer's instructions.

RT-PCR for PTEN expression. Total RNA was extracted from cells with Trizol reagent according to the manufacturer's instructions. An RT-PCR was carried out on Dnase Amp Grade (Gibco-Brl)-treated RNA using MuLV RT (50 units) in $100 \mathrm{mM}$ Tris- $\mathrm{HCl} \mathrm{pH} \mathrm{8.3,500} \mathrm{mM} \mathrm{KCl,} 5 \mathrm{mM} \mathrm{MgCl}_{2}$, $0.5 \mu \mathrm{M}$ each dNTP, 1 unit of RNasin, 500 pmol of random examer primers. Two microliters of cDNA were amplified in a $50 \mu 1$ reaction volume containing $0.5 \mu \mathrm{M}$ of sense and antisense primers, $2.5 \mathrm{U}$ of Taq DNA polymerase (Applied Biosystems, Milan, Italy), $200 \mu \mathrm{M}$ each dNTP and $1.5 \mathrm{mM}$ $\mathrm{MgCl}_{2}$. A co-amplification of GAPDH was performed. 

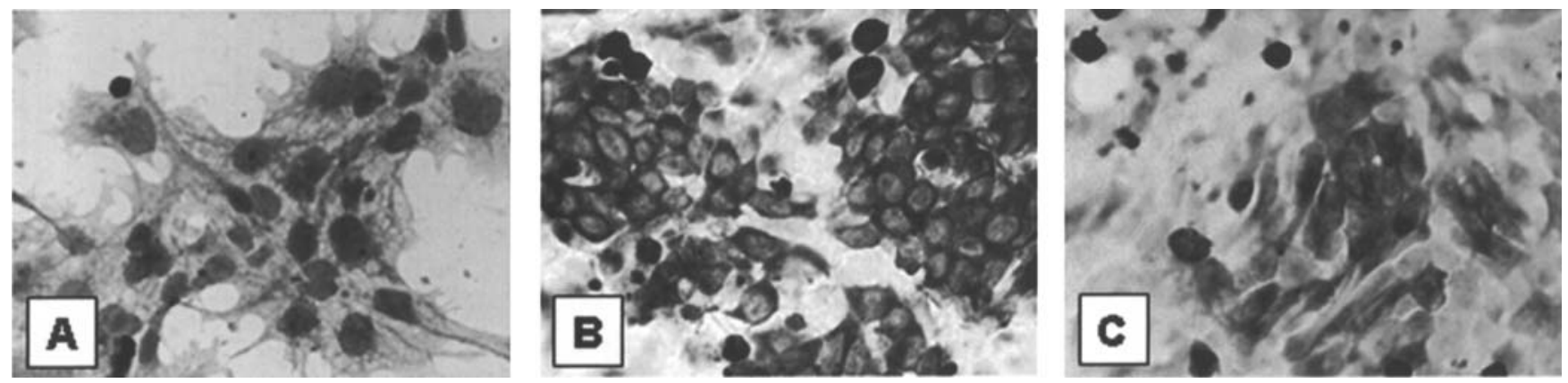

Figure 1. Immunocytochemistry for AR (A), EGFR (B) and Her2/neu expression (C) in a representative epithelial primary culture from PCa. Magnification x400.

Primer sequences used for PCR were: PTEN 3rd exon Fw 5'ATATTCTCTGAAAAGCTCTGG-3'; PTEN Rev 5'-TTA ATCGGTTTAGGAATCAA-3'; GAPDH Fw 5'-CACC ATGGAGAAAGGCCGGGG-3'; GAPDH Rev 5'-GACGGA CACATTGGGGGTAG-3'. After amplification, $20 \mu 1$ of the PCR reaction mixture was analysed by $1.2 \%$ agarose gel electrophoresis and stained with ethidium bromide.

Growth assays. Cells were seeded at a density of $2 \times 10^{4}$ cells per dish on 50-mm Petri dishes. Cells were allowed to attach and grow in 5\% FCS DMEM for $24 \mathrm{~h}$. After this time, cells were maintained in a culture medium containing androgens or subjected to androgen depletion. All other cells were treated with either $50 \mathrm{ng} / \mathrm{ml} \mathrm{EGF}$ or different doses of gefitinib and/or the PI3K inhibitor, perifosine, at the recommended inhibition doses. Cells trypsinised and re-suspended in $20 \mathrm{ml}$ saline were counted by a haemocytometer every $24 \mathrm{~h}$ (LabRecyclers, Gaithersburg, MD, USA) and 5 independent counts were performed for each dish. All experiments were conducted in triplicate. In order to evaluate the effective cell proliferation, we measured the uptake of $\left[{ }^{3} \mathrm{H}\right]$-tymidine as follows. To calculate the inhibitory concentrations at $50 \%\left(\mathrm{IC}_{50}\right)$ of gefitinib, 2,500 cells were cultured in 96-well plates for 24$96 \mathrm{~h}$. After adhesion (16 h), cells were grown in different culture conditions (see above). After 48-96 h, the cells were exposed for $4 \mathrm{~h}$ to thyazol blue (MTS, Promega Madison, WI, USA). The 96-well culture plates were then placed on a microplate shaker for $5 \mathrm{~min}$ and the absorbance of the converted dye was measured at the wavelength of $490 \mathrm{~nm}$ using a Biorad multiscan plate reader (Biorad, Richmond, CA, USA). Five replicate wells were used for each group. Inhibition curves were drawn by means of values obtained by OD percentages versus control for each concentration. $\mathrm{IC}_{50}$ values were calculated by the GraFit method (Erithacus Software Limited, Staines, UK) considering the slopes of inhibition curves obtained for each group of tests.

Apoptosis was evaluated by DNA fragmentation using a Titer TACS colorimetric assay kit (Trevigen Inc., Gaithersburg, MD, USA) and expressed as the percentage of cells that undergo apoptotic death.

Preparation of cell lysates and Western blot analysis. Following treatments, cells were washed with cold PBS and immediately lysed with $1 \mathrm{ml}$ lysis buffer (50 mM HEPES,
$\mathrm{pH} 7.5,150 \mathrm{mM} \mathrm{NaCl}, 10 \%$ glycerol, $1 \%$ Triton X-100, $1 \mathrm{mM}$ EDTA, $1 \mathrm{mM}$ EGTA, $50 \mathrm{mM} \mathrm{NaF}, 1 \mathrm{mM}$ sodium orthovanadate, $30 \mathrm{mM}$ p-nitrophenyl phosphate, $10 \mathrm{mM}$ sodium pyrophosphate, $1 \mathrm{mM}$ phenylmethylsulfonyl fluoride, $10 \mu \mathrm{g} /$ $\mathrm{ml}$ aprotinin and $10 \mu \mathrm{g} / \mathrm{ml}$ leupeptin). The nuclear extracts were collected as described: briefly, cells were scraped in $1 \mathrm{ml}$ PBS-EDTA and centrifuged at $3000 \mathrm{rpm}$. Pellets were resuspended in $1 \mathrm{ml}$ harvest buffer containing $10 \mathrm{mM}$ HEPES, $\mathrm{pH} 7.9,50 \mathrm{mM} \mathrm{NaCl}, 0.5 \mathrm{M}$ sucrose, $0.1 \mathrm{mM}$ EDTA and $0.5 \%$ Triton $\mathrm{X}-100$ and incubated on ice for $5 \mathrm{~min}$. Cells were pelleted at $1000 \mathrm{rpm}$ with a table top swinging microfuge, washed and re-suspended in $1 \mathrm{ml}$ of $10 \mathrm{mM}$ HEPES pH 7.9 containing $10 \mathrm{mM} \mathrm{KCl}, 0.1 \mathrm{mM}$ EDTA and $0.1 \mathrm{mM}$ EGTA. Lysates were electrophoresed in 7\% SDS-PAGE and separated proteins transferred to nitrocellulose and probed with the appropriate antibodies using the conditions recommended by the suppliers. The EGFR or ERK activation status was analysed using phosphospecific antibodies, blots were stripped and reprobed with the appropriate antibody for assessment of total ERK or EGFR expression.

Statistics. Statistical analysis was performed using SPSS 11.0 software (SPSS, Inc., Chicago, IL). P values $<0.05$ were considered to indicate statistical significance. All statistical tests were two-tailed. Continuous variables were analyzed using a Wilcoxon-Mann Whitney Rank Sum Test or Student's t-test when appropriate. Differences in the categorical variables between groups were compared with the Chi-square test or Fisher's exact test when the tables were too sparse. The Kruskal Wallis test was used to compare apoptosis in primary cultures.

\section{Results}

Effect of gefitinib and its correlation with EGFR, Her2 and $P T E N$ expression. Epithelial prostate primary cultures showed a homogeneous expression for AR and EGFR as indicated in Fig. 1 (panels A and B). Her2/neu positivity was present in $20-60 \%$ of cells (Fig. 1C). In addition, we showed that EGFR expression, by Western blotting analysis (Fig. 2), was higher, but not in a statistically significant manner, in cultures derived from patients from the NHT group when compared to the control (UNT) patients (2.5 normalized Arbitrary Densitometric Units $(\mathrm{ADU}) \pm 0.3$ vs $1.7 \mathrm{ADU} \pm 0.3, \mathrm{P}=0.075)$. EGFR 


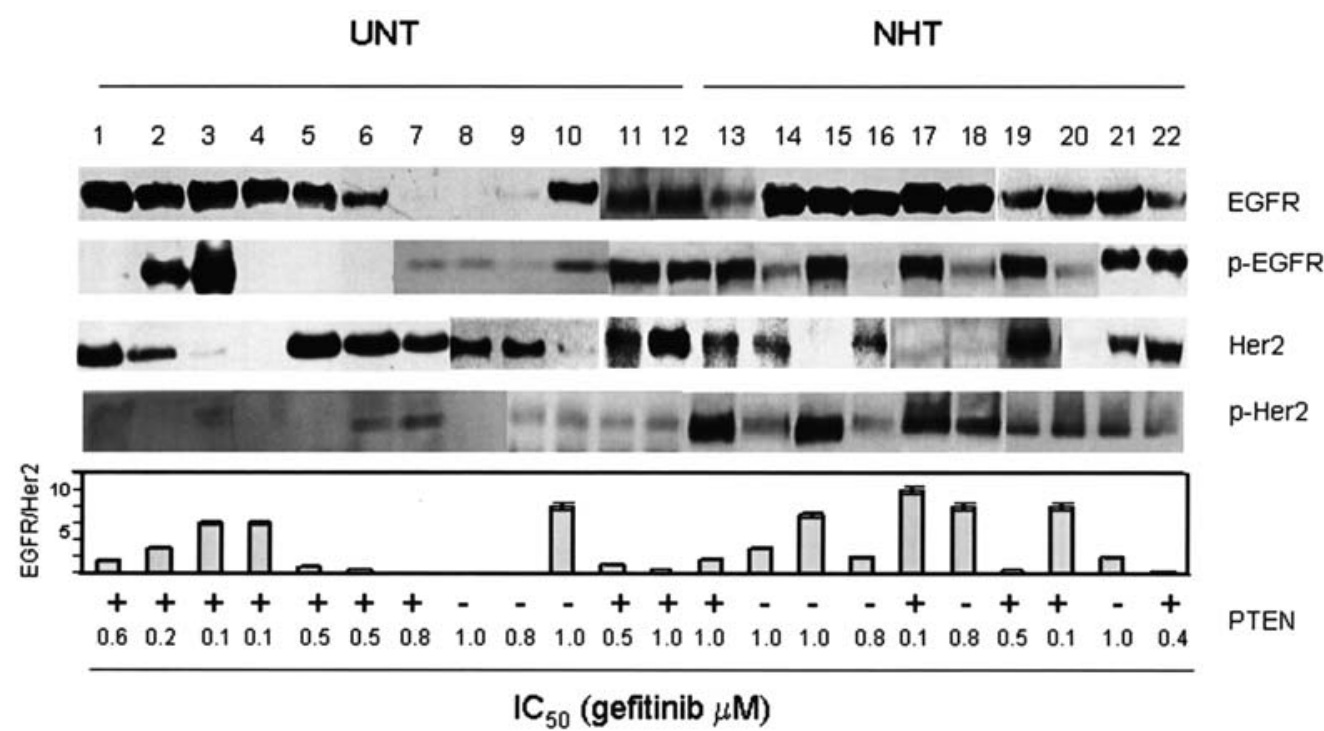

Figure 2. Western Blot analysis of EGFR/p-EGFR and Her2/p-Her2 expression levels in primary cultures derived from 22 PCa tissues of patients who underwent NHT (10 patients) or not (12 patients) as described in Material and methods. Each lane was loaded with $50 \mu \mathrm{g}$ of proteins from total cell extracts and normalized in each experiment with a common cell extract with known EGFR and Her2 content (we used conventionally DU145 cell extract). EGFR and Her2 were expressed also as a ratio between their levels in each culture. PTEN expression was evaluated both RT-PCR and Western blotting and indicated in the figure as presence (+) or absence (-) of PTEN protein. $\mathrm{IC}_{50}$ values from gefitinib were calculated as described (lower panel).

was basally phosphorylated in $8 / 12(66.7 \%)$ and in $9 / 10$ $(90 \%)$ of primary cultures derived from the UNT and NHT groups, respectively $(\mathrm{P}=0.430, \mathrm{NS})$ and the levels of phosphorylation were higher in the NHT group when compared to the UNT group (0.88 ADU \pm 0.37 vs 1.94 ADU $\pm 0.36, \mathrm{P}=0.059$ ), but this difference was not statistically significant. Her2 expression (Fig. 2) was similar in primary cultures derived from NHT patients when compared to UNT patients (1.1 ADU \pm 0.4 for both groups). Her2 was basally phosphorylated in 6/12 (50\%) and in 9/10 (90\%) of cultures derived from the control and NHT groups, respectively $(\mathrm{P}=0.122, \mathrm{NS})$ and the levels of $\mathrm{p}-\mathrm{Her} 2$ were significantly higher in the NHT patients when compared to the UNT patients $(0.2 \mathrm{ADU} \pm 0.8$ vs $1.8 \mathrm{ADU} \pm 0.8, \mathrm{P}<0.001)$. The blockade of EGFR/Her2 signalling pathways by gefitinib was able to reduce cell proliferation with $\mathrm{IC}_{50}$ ranging between 0.1$1.0 \mu \mathrm{M}$ as indicated in Fig. 2. $\mathrm{IC}_{50}$ mean value of gefitinib, calculated for all 22 cell cultures independent of the treatment of patients, was $0.62 \mu \mathrm{M} \pm 0.74$ (mean $\pm \mathrm{SD})$. When we considered the neoadjuvant pre-operative treatment, we did not observe any statistically significant difference for this parameter $(0.59 \mu \mathrm{M} \pm 0.97$ vs $0.67 \mu \mathrm{M} \pm 1.16, \mathrm{P}=0.608, \mathrm{NS})$. We then performed a correlation analysis between EGFR levels and $\mathrm{IC}_{50}$ values for gefitinib, but we did not observe any statistical relationship $(\mathrm{R}=-0.241 ; \mathrm{P}=0.280)$. Thus, the effectiveness of gefitinib was not dependent upon EGFR levels as previously reported by us (35) and others $(36,37)$. The same correlation assay was performed between $\mathrm{IC}_{50}$ values and Her2 levels, though we did not observe any significant correlation $(\mathrm{R}=0.241 ; \mathrm{P}=0.252)$.

Considering the PTEN expression, we observed that gefitinib was more effective in PTEN positive respect to PTEN negative cultures $(0.48 \mu \mathrm{M} \pm 0.85$ vs $0.92 \mathrm{mM} \pm 0.37$, $\mathrm{P}<0.001)$ as indicated in our previous paper (35). Although we observed that $3 / 12(25 \%)$ cultures were negative for PTEN expression in the UNT group and 5/10 (50\%) in the NHT group, this difference was not statistically significant $(\mathrm{P}=0.442$, NS $)$.

Considering both Her2 expression and EGFR/Her2 ratio in the PTEN positive population, we observed that the effectiveness of gefitinib was inversely related to Her2 levels $(\mathrm{R}=0.721, \mathrm{P}=0.004)$ and with a stronger correlation to EGFR/Her2 ratio $(\mathrm{R}=-0.852, \mathrm{P}<0.001)$ suggesting that in the presence of PTEN, the blockade of the EGFR pathway is more effective when the levels of Her2 were low and when the EGFR/Her2 ratio was high.

Combination treatment with bicalutamide and gefitinib. We previously demonstrated that EGF is able to induce AR translocation and PSA secretion by EGFR-dependent mechanisms and gefitinib was able to reduce AR-mediated PSA secretion (38). We also demonstrated that bicalutamide and gefitinib were additive/synergistic in the cell proliferation reduction and apoptosis induction (38) and that hydroxyflutamide treatment was able to induce EGFR and Her2 expression and sensitize to dual EGFR/Her2 inhibition by PKI166 (39).

In this study, we evaluated the differences of sensitivity of dual treatment in cultures derived from patients who underwent NHT or not. We demonstrated that the $\mathrm{IC}_{50}$ mean value of BCLT calculated for all 22 cell cultures independent of the treatment of patients was $1.04 \pm 0.67 \mu \mathrm{M}$ (mean \pm SD) in agreement with our previous data (38). When we considered the NHT, we observed that the differences were not statistically significant in respect to untreated patients $(0.97$ \pm 0.22 vs $1.13 \pm 0.21 \mu \mathrm{M}$, respectively, NS).

In the presence of gefitinib at $0.5 \mu \mathrm{M}$, bicalutamide inhibited cellular proliferation with $\mathrm{IC}_{50}$ values ranging between 0.1 and $0.4 \mu \mathrm{M}(0.25 \pm 0.14 \mu \mathrm{M})$ in primary cultures derived from $\mathrm{PCa}$ tissues. We observed that gefitinib and 

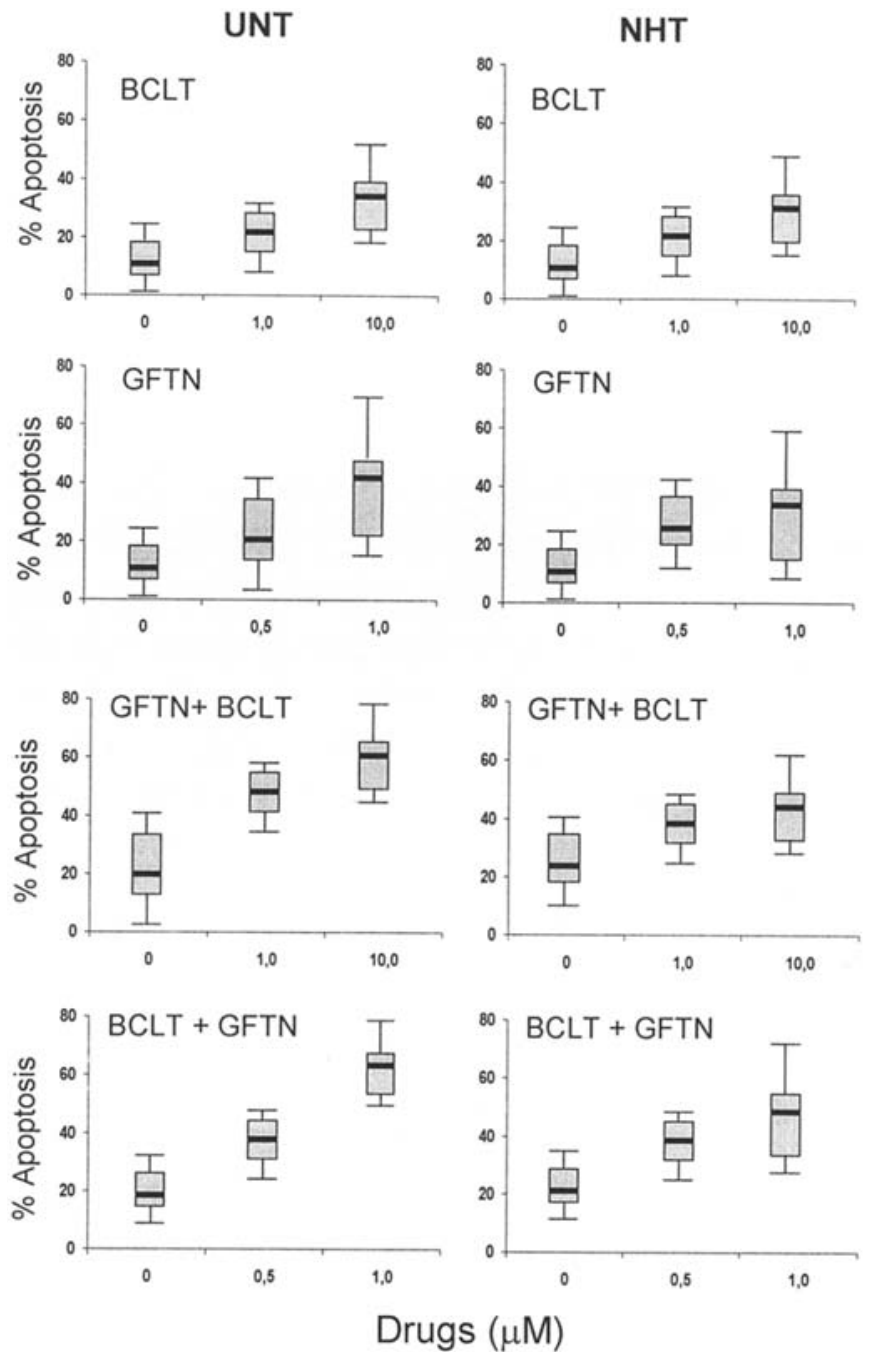

Figure 3. Apoptosis was evaluated using a DNA fragmentation by Titer TACS colorimetric kit and expressed as a percentage of apoptotic cells. Primary tumor cultures were treated for $48 \mathrm{~h}$ with 1.0 and $10.0 \mu \mathrm{M}$ bicalutamide (BCLT), 0.5 and $1.0 \mu \mathrm{M}$ gefitinib (GFTN), fixed $0.5 \mu \mathrm{M}$ GFTN and 1.0 and $10.0 \mu \mathrm{M}$ BCLT and fixed $1.0 \mu \mathrm{M}$ BCLT and 0.5 and $1.0 \mu \mathrm{M}$ GFTN.

BCLT showed no additive $(4 / 10,40 \%)$ or partially additive $(6 / 10,60 \%)$ effects in cultures derived from the NHT group whereas the effects were additive $(5 / 12,41.7 \%)$ or synergistic $(7 / 12,58.3 \%)$ in cultures derived from the control group, suggesting that the molecular modifications induced by hormonal therapy (EGFR, Her2 increased expression and PTEN loss acceleration) can negatively influence the effectiveness of dual inhibition. This suggestion was particularly reinforced observing data on apoptosis evaluated as DNA fragmentation using a Titer TACS colorimetric kit (Fig. 3). We observed that apoptosis was increased in a dosedependent manner by BCLT without any significant differences between UNT and NHT groups of cultures. Similarly, gefitinib (GFTN) sensitively stimulated the apoptotic death both in the UNT and NHT group. The NHT group showed a lower apoptotic death although the difference was not statistically significant. Moreover combination treatments showed synergistic effects in the UNT group whereas these were only additive in the NHT group.

\section{Discussion}

We previously demonstrated that AR-transfected DU145 cells treated with an antiandrogen, such as hydroxyflutamide, were more sensitive to the action of EGFR-tyrosine kinase inhibitor, PKI166 (39) due to the increased expression of EGFR. Thus, we hypothesized that the treatment with antiandrogens could effectively increase the sensitivity versus gefitinib. For these purposes, we verified the action of gefitinib in primary cultures derived from prostate cancer tissues that patients were treated with the sole radical prostatectomy or with neoadjuvant therapy based on bicalutamide treatment. The aim of this work was to evaluate if the hormonal therapy with BCLT can affect the EGFR targeted therapy. Previously, we demonstrated that expression of EGFR and Her2 increases significantly after hormone therapy performed in a neoadjuvant regimen (40). Here, we demonstrated that epithelial prostate cells in primary cultures derived from samples harvested from PCa after NHT showed higher levels of Her1 and Her2 compared to control PCa cultures as well as the levels of activated form of receptors are increased also if the differences were statistically not significant probably due to the small number of cultures examined. The block of EGFR/ Her2 signalling pathways by gefitinib were able to reduce cell proliferation and we did not observe statistically significant differences between cultures derived from NHT and UNT patients suggesting that globally the effects of gefitinib were maintained. Although the difference in PTEN expression was not statistically significant, we observed that $3 / 12(25 \%)$ cultures were negative for PTEN expression in UNT group and 5/10 (50\%) in the NHT group and gefitinib was more effective in PTEN-positive respect to PTENnegative cultures as indicated previously (35). We observed that the effects of gefitinib were not related to EGFR levels, as previously observed by us (35) and others $(36,37)$ as to Her2 levels. However, considering both Her2 expression and EGFR/Her2 ratio in the more responder PTEN-positive population, we observed that the effectiveness of gefitinib was inversely related to Her2 levels as well as to EGFR/Her2 ratio suggesting that when PTEN is present, the blockade of the EGFR pathway is more effective if the levels of Her2 were low and if the EGFR/Her2 ratio was high.

The role of c-erbB-2 in prostate cancer is also controversial, contrary to this receptor's clinical importance only for advanced breast cancer (41). Both c-erbB-1 and c-erbB-2 immunoreactivity were shown to be associated with an unfavorable prognosis in a homogeneous series of hormonally untreated cancer patients, in particular if these two receptors are combined (42).

The effectiveness of BCLT did not seem to be different in the two groups and was partially additive with gefitinib in NHT group and additive/synergistic in the control group. Thus, the different $\mathrm{IC}_{50}$ values observed for gefitinib and the partial additivity in the combination treatment with gefitinib and bicalutamide can be influenced by EGFR/Her2 ratio because it was shown that EGFR inhibition was lower when Her2 is overexpressed. However, it needs to be considered that the AR expression could slow down the EGFR phosphorylation due its membrane co-localization as observed from Bonaccorsi and co-workers (43). In addition we observed 
that the combination treatment regimens show higher effects in cultures derived from UNT in respect to NHT patient groups suggesting that the molecular modifications induced by hormonal therapy (EGFR, Her2 increased expression and PTEN loss acceleration) can negatively influence the effectiveness of dual inhibition. The data suggest that antiEGFR targeted therapies and combination therapeutic approach involving gefitinib and BCLT should be performed earlier in naive patients when Her2 is not overexpressed and before any possible hormone therapy induces this event.

\section{References}

1. De Marzo AM, Putzi MJ and Nelson WG: New concepts in the pathology of prostatic epithelial carcinogenesis. Urology 57: 103-114, 2001.

2. Osman I, Scher HI, Drobnjak M, et al: C.HER-2/neu (p185neu) protein expression in the natural or treated history of prostate cancer. Clin Cancer Res 7: 2643-2647, 2001.

3. Di Lorenzo G, Tortora G, D'Armiento FP, et al: Expression of epidermal growth factor receptor correlates with disease relapse and progression to androgen-independence in human prostate cancer. Clin Cancer Res 8: 3438-3444, 2002.

4. Calvo BF, Levine AM, Marcos M, et al: Human epidermal receptor-2 expression in prostate cancer. Clin Cancer Res 9: 1087-1097, 2003

5. Hernes E, Fossa SD, Berner A, et al: Expression of the epidermal growth factor receptor family in prostate carcinoma before and during androgen-independence. Br J Cancer 90: 449-454, 2004.

6. Osman I, Mikhail M, Shuch B, et al: Serum levels of shed Her2/neu protein in men with prostate cancer correlate with disease progression. J Urol 174: 2174-2177, 2005.

7. Okegawa T, Kinjo M, Nutahara K and Higashihara E: Pretreatment serum level of HER2/neu as a prognostic factor in metastatic prostate cancer patients about to undergo endocrine therapy. Int J Urol 13: 1197-1201, 2006.

8. Montironi R, Mazzucchelli R, Barbisan F, et al: HER2 expression and gene amplification in pT2a Gleason score 6 prostate cancer incidentally detected in cystoprostatectomies: comparison with clinically detected androgen-dependent and androgenindependent cancer. Hum Pathol 37: 1137-1144, 2006.

9. Gregory CW, Whang YE, McCall W, et al: Heregulin-induced activation of HER2 and HER3 increases androgen receptor transactivation and CWR-R1 human recurrent prostate cancer cell growth. Clin Cancer Res 11: 1704-1712, 2005.

10. Liu Y, Majumder S, McCall W, et al: Inhibition of HER-2/neu kinase impairs androgen receptor recruitment to the androgen responsive enhancer. Cancer Res 65: 3404-3409, 2005.

11. Berger R, Lin DI, Nieto M, et al: Androgen-dependent regulation of Her-2/neu in prostate cancer cells. Cancer Res 66: 5723-5728, 2006.

12. Lara PN Jr, Chee KG, Longmate J, et al: Trastuzumab plus docetaxel in HER-2/neu-positive prostate carcinoma: final results from the California Cancer Consortium Screening and Phase II Trial. Cancer 100: 2125-2131, 2004.

13. Ziada A, Barqawi A, Glode LM, et al: The use of trastuzumab in the treatment of hormone refractory prostate cancer: phase II trial. Prostate 60: 332-337, 2004.

14. de Bono JS, Bellmunt J, Attard G, Droz JP, et al: Open-label phase II study evaluating the efficacy and safety of two doses of pertuzumab in castrate chemotherapy-naive patients with hormone-refractory prostate cancer. J Clin Oncol 25: 257-262, 2007.

15. Agus DB, Sweeney CJ, Morris MJ, et al: Efficacy and safety of single-agent pertuzumab (rhuMAb 2C4), a human epidermal growth factor receptor dimerization inhibitor, in castrationresistant prostate cancer after progression from taxane-based therapy. J Clin Oncol 25: 675-681, 2007.

16. Agus DB, Scher HI, Higgins B, et al: Response of prostate cancer to anti-Her-2/neu antibody in androgen-dependent and independent human xenograft models. Cancer Res 59: 4761-4764, 1999.

17. DeGrendele H: The anti-HER2 monoclonal antibody pertuzumab may be effective in androgen-independent prostate cancer. Clin Prostate Cancer 2: 143-145, 2003.
18. Edwards J, Traynor P, Munro AF, et al: The role of HER1-HER4 and EGFRvIII in hormone-refractory prostate cancer. Clin Cancer Res 12: 123-130, 2006.

19. Ciardiello F, Caputo R, Bianco R, et al: Antitumor effect and potentiation of cytotoxic drugs activity in human cancer cells by ZD-1839 (Iressa), an epidermal growth factor receptor-selective tyrosine kinase inhibitor. Clin Cancer Res 6: 2053-2063, 2000.

20. Sirotnak FM, Zakowski MF, Miller VA, et al: Efficacy of cytotoxic agents against human tumor xenografts is markedly enhanced by coadministration of ZD1839 (Iressa), an inhibitor of EGFR tyrosine kinase. Clin Cancer Res 6: 4885-4892, 2000.

21. Ciardiello F, Caputo R, Bianco R, et al: Inhibition of growth factor production and angiogenesis in human cancer cells by ZD1839 (Iressa), a selective epidermal growth factor receptor tyrosine kinase inhibitor. Clin Cancer Res 7: 1459-1465, 2001.

22. Moasser MM, Basso A, Averbuch SD and Rosen N: The tyrosine kinase inhibitor ZD1839 ('Iressa') inhibits HER2-driven signaling and suppresses the growth of HER2-overexpressing tumor cells. Cancer Res 61: 7184-7188, 2001.

23. Moulder SL, Yakes FM, Muthuswamy SK, et al: Epidermal growth factor receptor (HER1) tyrosine kinase inhibitor ZD1839 (Iressa) inhibits HER2/neu (erbB2)-overexpressing breast cancer cells in vitro and in vivo. Cancer Res 61: 8887-8895, 2001.

24. Bianco C, Tortora G, Bianco R, et al: Enhancement of antitumor activity of ionizing radiation by combined treatment with the selective epidermal growth factor receptor-tyrosine kinase inhibitor ZD1839 (Iressa). Clin Cancer Res 8: 3250-3258, 2002.

25. Ciardiello F, Caputo R, Borriello G, Del Bufalo D, Biroccio A, Zupi G, Bianco AR and Tortora G: ZD1839 (IRESSA), an EGFR-selective tyrosine kinase inhibitor, enhances taxane activity in bcl-2 overexpressing, multidrug-resistant MCF-7 ADR human breast cancer cells. Int J Cancer 98: 463-469, 2002.

26. Fujimura M, Hidaka T and Saito S: Selective inhibition of the epidermal growth factor receptor by ZD1839 decreases the growth and invasion of ovarian clear cell adenocarcinoma cells. Clin Cancer Res 8: 2448-2454, 2002.

27. Huang SM, Li J, Armstrong EA and Harari PM: Modulation of radiation response and tumor-induced angiogenesis after epidermal growth factor receptor inhibition by ZD1839 (Iressa). Cancer Res 62: 4300-4306, 2002.

28. Janne PA, Taffaro ML, Salgia R and Johnson BE: Inhibition of epidermal growth factor receptor signaling in malignant pleural mesothelioma. Cancer Res 62: 5242-5247, 2002.

29. Magne N, Fischel JL, Dubreuil A, et al: Sequence-dependent effects of ZD1839 ('Iressa') in combination with cytotoxic treatment in human head and neck cancer. Br J Cancer 86: 819-827, 2002.

30. Williams KJ, Telfer BA, Stratford IJ and Wedge SR: ZD1839 ('Iressa'), a specific oral epidermal growth factor receptor-tyrosine kinase inhibitor, potentiates radiotherapy in a human colorectal cancer xenograft model. Br J Cancer 86: 1157-1161, 2002.

31. Bologna M, Vicentini C, Festuccia C, et al: Early diagnosis of prostatic carcinoma based on in vitro culture of viable tumor cells harvested by prostatic massage. Eur Urol 14: 474-476, 1988.

32. Bologna M, Vicentini C, Festuccia C, et al: Short-term tissue culture of prostatic carcinoma samples provides useful biological parameters related to patient prognosis. Eur Urol 15: 243-247, 1988.

33. Festuccia C, Angelucci A, Gravina GL, et al: Epithelial and prostatic marker expression in short-term primary cultures of human prostate tissue samples. Int J Oncol 26: 1353-1362, 2005.

34. Vicentini C, Gravina GL, Angelucci A, et al: Detection of telomerase activity in prostate massage samples improves differentiating prostate cancer from benign prostatic hyperplasia. J Cancer Res Clin Oncol 130: 217-221, 2004.

35. Festuccia C, Muzi P, Millimaggi D, et al: Molecular aspects of gefitinib antiproliferative and pro-apoptotic effects in PTENpositive and PTEN-negative prostate cancer cell lines. Endocr Relat Cancer 12: 983-998, 2005.

36. Helfrich BA, Raben D, Varella-Garcia M, et al: Antitumor activity of the epidermal growth factor receptor (EGFR) tyrosine kinase inhibitor gefitinib (ZD1839, Iressa) in non-small cell lung cancer cell lines correlates with gene copy number and EGFR mutations but not EGFR protein levels. Clin Cancer Res 12: 7117-7125, 2006.

37. Parra HS, Cavina R, Latteri F, et al: Analysis of epidermal growth factor receptor expression as a predictive factor for response to gefitinib ('Iressa', ZD1839) in non-small-cell lung cancer. Br J Cancer 91: 208-212, 2004. 
38. Festuccia C, Gravina GL, Angelucci A, et al: Additive antitumor effects of the epidermal growth factor receptor tyrosine kinase inhibitor, gefitinib (Iressa), and the nonsteroidal antiandrogen, bicalutamide (Casodex), in prostate cancer cells in vitro. Int $\mathbf{J}$ Cancer 115: 630-640, 2005

39. Gravina GL, Festuccia C, Angelucci A, et al: Long-term presence of androgens and anti-androgens modulate EGF-receptor expression and MAP-kinase phosphorylation in androgen receptor-prostate positive cancer cells. Int J Oncol 25: 97-104, 2004.

40. Gravina GL, Festuccia C, Paradiso Galatioto G, et al: Bicalutamide before surgery induces changes in tumor molecular arrangements and reduces the positive margins in prostate cancers. Urology (In press).
41. Cobleigh MA, Vogel CL, Tripathy D, et al: Multinational study of the efficacy and safety of humanized anti-HER2 monoclonal antibody in women who have HER2-overexpressing metastatic breast cancer that has progressed after chemotherapy for metastatic disease. J Clin Oncol 17: 2639-2648, 1999.

42. Slamon DJ, Leyland-Jones B, Shak S, et al: Use of chemotherapy plus a monoclonal antibody against HER2 for metastatic breast cancer that overexpresses HER2. N Engl J Med 344: 783-792, 2001.

43. Bonaccorsi L, Nosi D, Muratori M, Formigli L, Forti G and Baldi E: Altered endocytosis of epidermal growth factor receptor in androgen receptor positive prostate cancer cell lines. J Mol Endocrinol 38: 51-66, 2007. 